\author{
5軸マイクロレーザー加工装置の開発 \\ 河村 良行, 竹中篤司 \\ 福岡工業大学 工学部電子機械工学科（广 811-0295 福岡市東区和白東3-30-1）

\section{Development of a Five Axis Laser Micromachining System} \\ Yoshiyuki KAWAMURA and Atusi TAKENAKA \\ Department of Electronic and Mechanical Engineering, Faculty of Engineering, Fukuoka Institute of Technology \\ 3-30-1 Wajirohigashi, Higashi-ku, Fukuoka 811-0295 \\ (Received June 26, 1998)

\begin{abstract}
A five axis laser micromachining system has been developed, that can be used for the laser machining of threedimensional micro structures. Using an appropriate correction for the eccentric displacement between the rotational axes and the center axis of the target, the patterning of longitude lines and latitude lines has been successfully performed on the spherical surface of a miniature still ball with a diameter of $1.2 \mathrm{~mm}$. $\mathrm{C}_{60}$-like geometry (soccer ball pattern) has also been successfully fabricated on this still ball.
\end{abstract}

Key Words: Micromachining, Five axis, Laser machining, Soccer ball

\section{1.はじめに}

我々がこれまでに開発したレーザー旋盤加工法1-3)では， 加工物を動かせる自由度は通常の旋盤と同じ2個であり,加 工できる形状に制限があった。本研究ではレーザー旋盤 加工法で加工できない複雑な形状の加工を行うために, 加 工物の移動及び回転の自由度を新たに3個つけて加え合計 5個とし, 5軸マイクロレーザー加工装置を開発した.

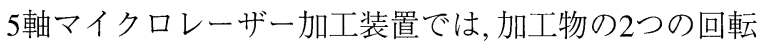
軸とレーザー光の光軸を互いに正確に直交させることが, 光軸合わせで最も重要になる. 特に, 2 つ回転軸に対する 微小球の取り付け偏心誤差により発生する回転運動をど の様にして修正・補正するかが, 5 軸マイクロレーザー加工 装置の開発の重要なポイントとなる.

本加工装置の最終目的は微小な立体形状の加工である

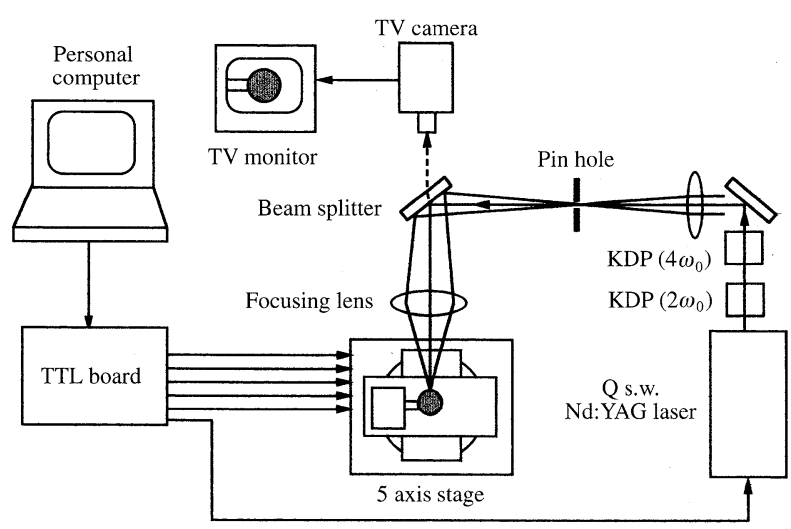

Fig.1 Five axis laser micromachining system.
が, 本稿では本装置を微小な球体の表面のパターニング4) に用いた結果について述べる。

\section{2. 実験システム}

Fig.1に実験装置の概略を示す。加工用のレーザーはQ スイッチYAGレーザーの4倍波であり, システム制御用の パソコンにより必要に応じて作動させることが出来る. 直径 $1 \mathrm{~mm}$ のピンホールの像をターゲット上に転送する, 像 転送光学系により,最小集光径は約 $30 \mu \mathrm{m}$ となる. Fig.2に示 すX軸, Y軸, Z軸の3個の直線軸移動及び, $\omega$ 軸, $\theta$ 軸の 2 個の 回転軸移動が, パルスモーター駆動の5個の精密ステージに より可能である。これらの精密ステージはパソコンから のTTL信号により駆動されている。ビームスプリッターを 透過する加工物の可視光の像はカラーCCD上に結像され,

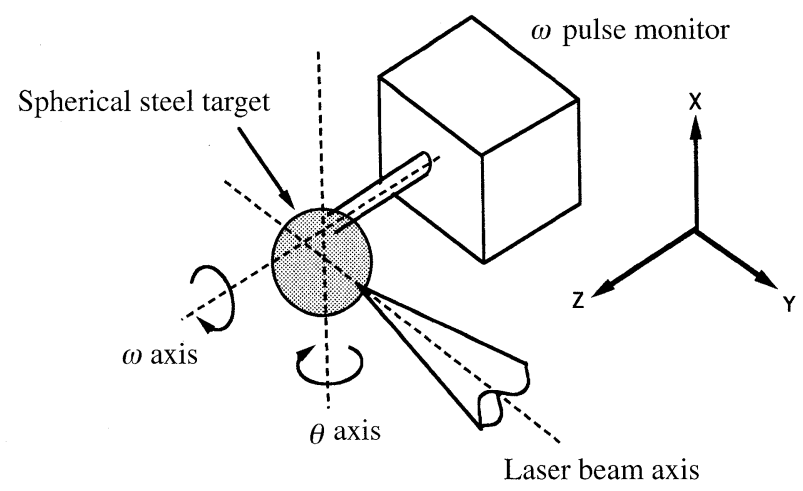

Fig.2 Three linear axes and two rotational axes which compose five freedoms of motion. 
テレビのモニター上に映し出される。モニター上では, 走 查線の一間隔は約 $5 \mu \mathrm{m}$ に相当し,ターゲットの相対的な位 置の変化をほぼ5 $\mu \mathrm{m} の$ 精度で観測することが出来る．加工 のプログラムはC 言語により記述され, 数 $\mathrm{kHz}$ の信号処理が 可能であるが, 加工速度はレーザー装置の繰り返し速度の $10 \mathrm{~Hz}$ で律速されている.

\section{3. ターゲット取り付け偏心誤差の修正法}

\section{$3.1 \omega$ 軸回転に関する修正}

の軸の回転による球状ターゲットの偏心運動を防ぐに は， $\omega$ 軸上に球状ターゲットの中心を合わせる必要があ る. Fig.2に示されるように, 球状ターゲットは直接 $\omega$ 軸に 取り付けられている. Fig.3に示すように,一般に球状夕ー ゲットは $\omega$ 回転軸から偏心した状態で取り付けられている ので, $\omega$ 軸が回転するとターゲットの中心は回転運動を行 う.この偏心運動は, レーザー光の照射位置とターゲット の相対的位置関係をずらすので, 精密な加工の妨げとな る. 本研究では, この偏心誤差を修正するための手法とし て, $\omega$ 軸に垂直な方向の運動を与える2つの移動ステージ $(\mathrm{X}$ ステージ, Zステージ)で, 時々刻々この偏心を補正する方 法を考案し,その効果を実験的に検証した。

Fig.4に示すように,この偏心運動は偏心距離を $r$ とすると 半径 $r$ の軌道になる。 このとき, 偏心補正べクトルを $A_{n}$, $\omega$ 軸の回転角を $\omega_{n}$ とすると

$$
\boldsymbol{A}_{n}=\left(r\left(1-\cos \omega_{n}\right),-r \sin \omega_{n}\right)
$$

となる。また, Xステージ及びYステージのn-1ステップか らnステップへの移動量は $\boldsymbol{A}_{n}$ の差分で与えられ,これを $\boldsymbol{B}_{n}$ とすると

$$
\begin{aligned}
\boldsymbol{B}_{n} & =\boldsymbol{A}_{n}-\boldsymbol{A}_{n-1} \\
& =\left(r\left(\cos \omega_{n}-\cos \omega_{n-1}\right),-r\left(\sin \omega_{n}-r \sin \omega_{n-1}\right)\right)
\end{aligned}
$$

となる。

偏心距離 $r$ は, $\theta$ 軸を360度回転させた時の球状ターゲッ トの軸振れを 90 度異なる方向からCCDテレビモニターによ り観測することにより,モニターの分解能と像の拡大率で

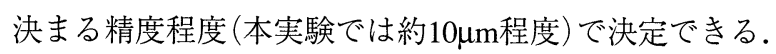

\section{$3.2 \theta$ 回転軸に関する修正}

$\theta$ 軸の回転による球状ターゲットの偏心運動を防ぐには,

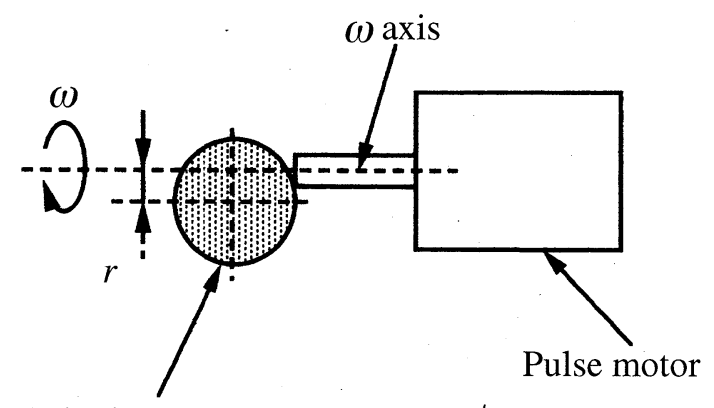

Spherical steel target $(1.2 \mathrm{~mm} \phi)$

Fig.3 Eccentric displacement between the axis of the spherical target and the rotational axis.

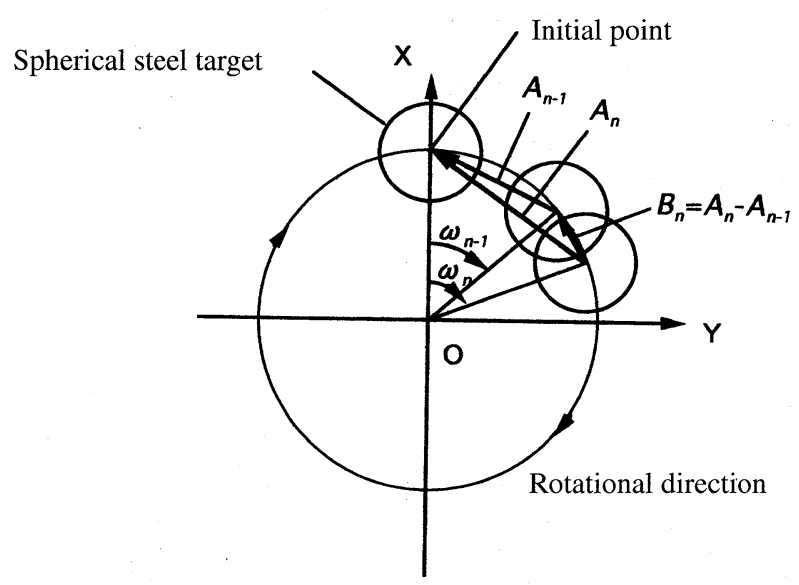

Fig.4 Correction vector of eccentric error and finite difference of this vector.

$\theta$ 軸上に球状ターゲットの中心を合わせる必要がある. Fig.2 に示されるように, 球状ターゲットは直接 $\theta$ 軸に取り 付けられているのではなく,Xステージ及びYステージを介 して 軸ステージに取り付けられているので, 3.1の場合の ような回転角に依存する補正は必要ではなくなる。 $\theta$ 軸に 対するターゲット中心の偏心量は, $\theta$ 軸を 360 度回転させた 時の球状ターゲットの軸振れ距離を90度異なる方向から CCDテレビモニターにより観測しながら, 徐々に減少させ るようにX及びYステージを調整することにより,モニター を用いてのターゲット位置観測の分解能程度まで収束さ せることが出来た。

\section{4. 実験結果}

\section{1 経線・緯線の描画}

球面上の任意の点に加工用のレーザー光を照射するた めには2つの回転の自由度が必要となる。本加工装置では この $2 つ の$ 回転軸として $\theta$ 軸及び $\omega$ 軸をとり, $1.2 \mathrm{~mm}$ のス チール球ターゲットを地球に見立て, $\omega$ 軸と球面の交わる 点を北極及び南極とする. 従って, 加工スポットは, $\omega$ 軸を 回転することにより一定の緯度上を移動し, また $\theta$ 軸を回転 することにより一定の経度上を移動することになる。こ の経線・緯線の描画精度から, 球面上での加工スポットの 位置合わせ精度を評価することが出来る。

Fig.5は偏心補正を行った場合の, 北極で交わる45度間隔 の8本の経線と北緯45度の緯線の描画を示す。(a) は北極の 真上から見たものであり,(b)はこれと垂直な方向から見た ものである. 偏心補正を行わないとき4組の経線の相対的 な角度関係は45度間隔で一定に正確に正しく保たれるが, これらの交点は一点で交わっていないのみならず,中心か らずれている。しかしながら, 補正を行った場合は, Fig.5 に示されるように4組の経線の相対的な角度関係は45度間 隔で一定に保たれているのみならず,これらの交点は一点 で交わっており,さらにこの交点の $\omega$ 軸からのずれは, 偏心 補正を行わない場合と比較してはるかに小さくなってい ることが明らかとなった。この結果から,回転軸に直交す る2つの直線移動ステージによる偏心の補正の有効性が, 実 験的に検証された。 


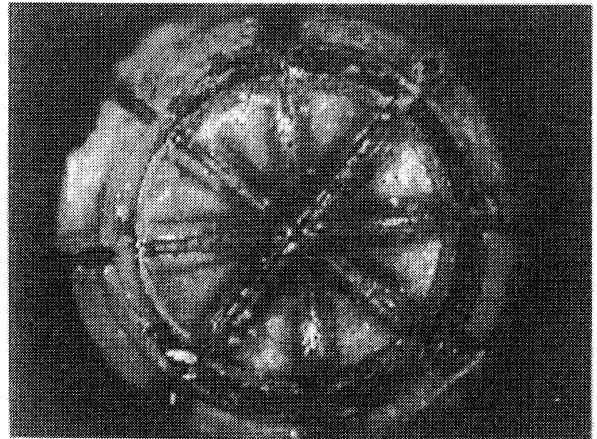

(a)

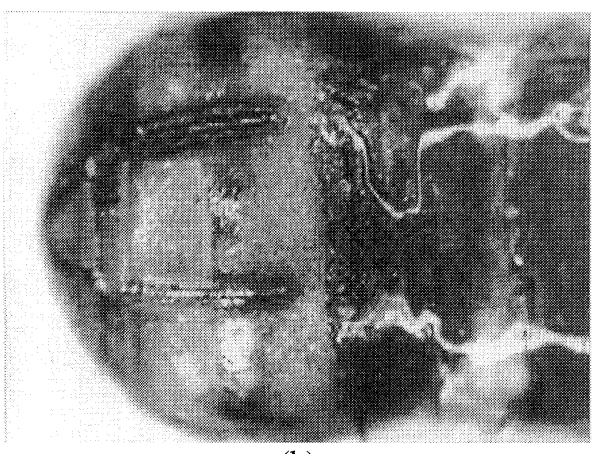

(b)

Fig.5 Patterning longitudes and latitudes on the spherical steel ball targets. (a) top view. (b) side view.

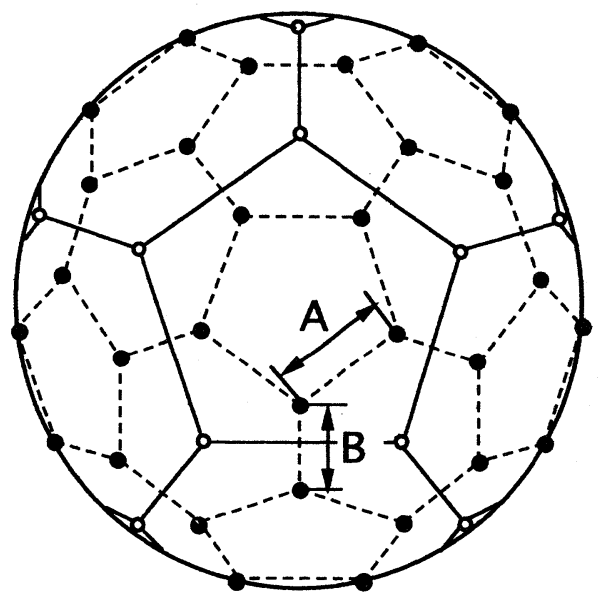

Fig.6 $\mathrm{C}_{60}$ like (soccer ball) pattern. Solid circles are the points on which the laser beam was focused.

\section{$4.2 \mathrm{C}_{60}$ 様パターンの描画}

$\mathrm{C}_{60}$ 状のパターンは Fig.6に示すように正十二面体の各々 の正五角形面の中心に, この面よりも小さい正五角形が配 置された形状になっている5). 従って描画は, 十二面体の 中心に加工スポットを移動し, 次にこの点を中心とする正 五角形を描画する,という手順をとった。描画においては, Fig.6に示されるA, Bの值を等しく取った.

Fig.7 に本研究により開発したレーザー加工システムを 用いて, $1.2 \mathrm{~mm}$ の鋼球上に加工した $\mathrm{C}_{60}$ 様のパターンの典型

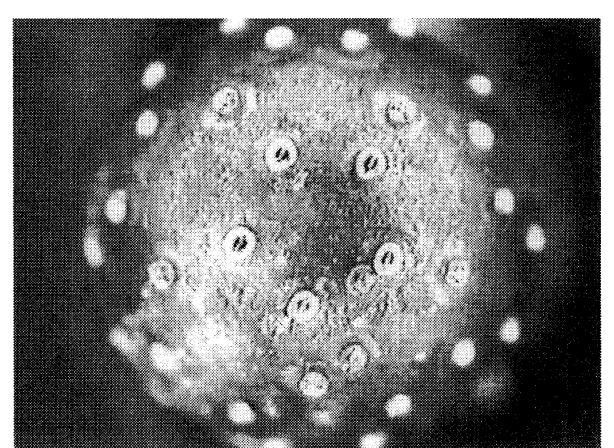

(a)

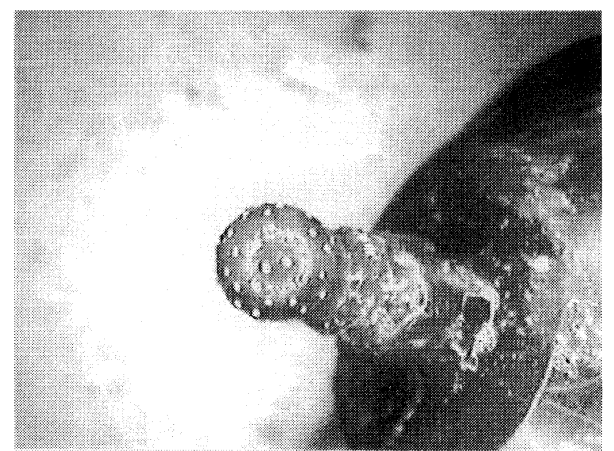

(b)

Fig.7 Fabrication of $\mathrm{C}_{60}$ like pattern on the surface of the spherical steel ball. (a) magnified view. (b) distant view.

的な加工例を示す. 加工点はFig.6 の中で黒点で示した60 個の点である. 加工物の取り付け偏心誤差を, 上述した手 法で, 補正することにより, ほぼ正確な形状の描画が可能 となった。

\section{5. 結 言}

5軸マイクロレーザー加工装置を開発し, 微小な球面ター ゲット上のパターニングを試みた。ターゲットを回転軸 に取り付ける時に生じる偏心誤差を補正するための手法 を開発した．直径 $1.2 \mathrm{~mm}$ の鋼球の表面上に経線・緯線及び $\mathrm{C}_{60}$ 様のパターニングを施し,この補正の効果を実証した.

本稿では, この加工システムが球面上の微細なパターニ ングに有効であることを示したが, 最終目的は微小な立体 形状の加工である.

\section{参考文献}

1) 河村 良行：電気学会研究会資料 OQD-95-57 63.

2) 河村 良行：レーザー研究 24 (1996) 460.

3) 河村 良行, 豊田 浩一：レーザー研究 23 (1995) 676.

4) R. J. Wallace, R. L. McEachern, and W. W. Wilcox: Inertial Confinement Fusion Quartry Progress Report, Lawrence Livermore National Lab. 14 (1994) 79.

5) M. Murakami: Annual Progress Report '96, Institute of Laser Engineering. 